DOI: https://doi.org/10.24867/03IH01Zivanov

\title{
RAZVOJ SISTEMA ZA NADZOR I UPRAVLJANJE TAKMIČENJEM U POZNAVANJU SAOBRAĆAJA
}

\section{DEVELOPMENT OF SYSTEM FOR SURVEILANCE AND CONTROL OF COMPETITION IN TRAFFIC RULES KNOWLEDGE}

\author{
Darko Živanov, Fakultet tehničkih nauka, Novi Sad
}

\section{Oblast - MEHATRONIKA}

Kratak sadržaj - U ovom radu predstavljen je razvoj sistema za upravljanje $i$ nadgledanje republičkog takmičenja u poznavanju saobraćaja. Dat je kratak prikaz iskorišćenih hardverskih komponenti, programiranje mikrokontrolera, programiranje android aplikacije $i$ međusobna komunikacija mikrokontrolera $i$ mobilnog uredjaja upotrebom blutut komunikacionog protokola.

Ključne reči: Takmičenje, Android aplikacija, Blutut

Abstract - The paper describe competition in traffic rules knowledge surveilance and control system development. A brief overview of the used hardware components, microcontroller programming, android application programming and communication between microcontroller and mobile device using a bluetooth communication protocol is provided.

Ključne reči: Competition, Android app, Bluetooth

\section{UVOD}

Zajednica srednjih saobraćajnih škola Republike Srbije svake godine organizuje takmičenje učenika srednjih saobraćajnih škola. Takmičenje se sastoji iz teoretskog $i$ praktičnog dela. Tokom godina pojavio se problem istinitosti i transparentnosti rezultata koji su takmičari postigli na praktičnom delu.

Cilj ovog rada je razvoj sistema koji se sastoji iz hardverskog i softverskog rešenja, kojim će se automatizovati proces praktičnog dela takmičenja srednjih saobraćajnih škola Republike Srbije i Android aplikacije koja će omogućiti skladištenje i čuvanje rezultata duži vremenski period i njihov transparentni pregled.

\section{ANALIZA ZADATKA}

U okviru što boljeg razumevanja problematike ovog rada, izložen je kratak opis takmičenja i tok procesa izvršenja zadataka od strane takmičara na poligonu. $\mathrm{Na}$ kraju prikazan je i dosadašnji razvoj upravljanja i nadzora ovog takmičenja.

Poligon sa zadatom putanjom, preprekama i zadacima koji se trebaju izvršiti prikazan je na slici 1 .

\section{NAPOMENA:}

Ovaj rad proistekao je iz master rada čiji mentor je bio dr Gordana Ostojić, van.prof.

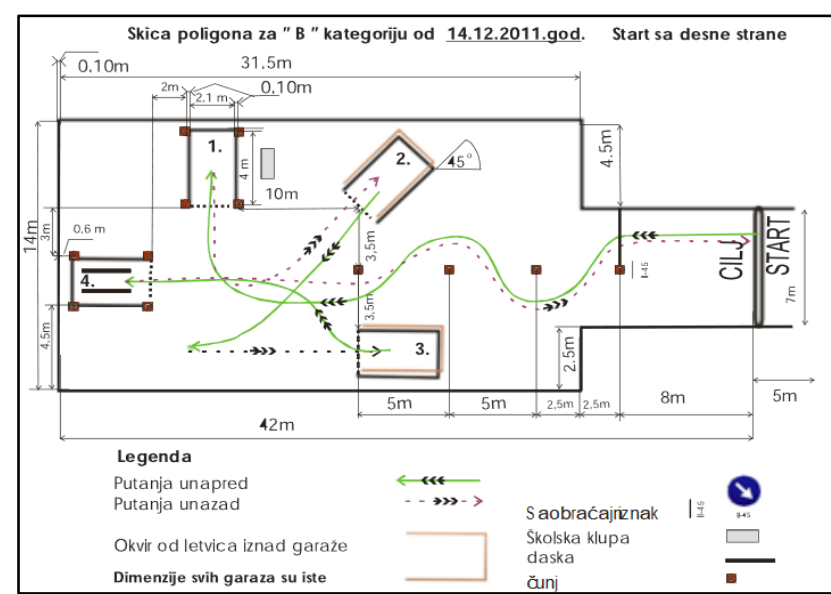

Slika 1: Skica poligona praktičnog dela takmičenja

Tok izrade praktičnih zadataka [1] je sledeći. Takmičar polazi sa startne pozicije. Nailaskom na prvi čunj počinje merenje vremena potrebnog za izvršenje svih zadataka. Prvi zadatak predstavlja cik cak prolazak između čunjeva. Sledeći zadatak je parkiranje vozila u ,garažu“ na poziciji 1 unapred. Potom takmičar izlazi iz vozila i rešava poseban zadatak na papiru.

Nakon toga takmičar se ponovo vraća u vozilo i vožnjom unazad parkira svoje vozilo u ,garažu“ na poziciji broj 2 . Parkiranje vozila hodom unazad u ,garažu“ na poziciji broj 3 je sledeći zadatak. Parkiranje na „kanal“ 4 se obavlja hodom unapred, nakon čega sledi vožnja vozila unazad između čunjeva. Pri prolasku pored u ovom slučaju poslednjeg čunja merenje proteklog vremena $u$ izvršavanju zadataka se zaustavlja.

Zadatak ovog rada je da prati jedan od parametara uspešnosti izvršenja zadataka i obezbedi merenje, memorisanje i prikaz njegove vrednosti. Taj parametar je proteklo vreme iskorišćeno u izvršenju istih.

\section{REŠENJE HARDVERA}

Hardver je realizovan upotrebom mikrokontrolera $u$ okruženju koji omogućava njegov pravilan rad, blutut modula i simulatora senzora položaja. Prototip tj. test uređaj prikazan je na slici 2. Razlog izbora ovog kontrolera jeste, pored karakteristika, prethodno stečeno iskustvo u radu sa ovom familijom kontrolera $\mathrm{u}$ toku školovanja. 


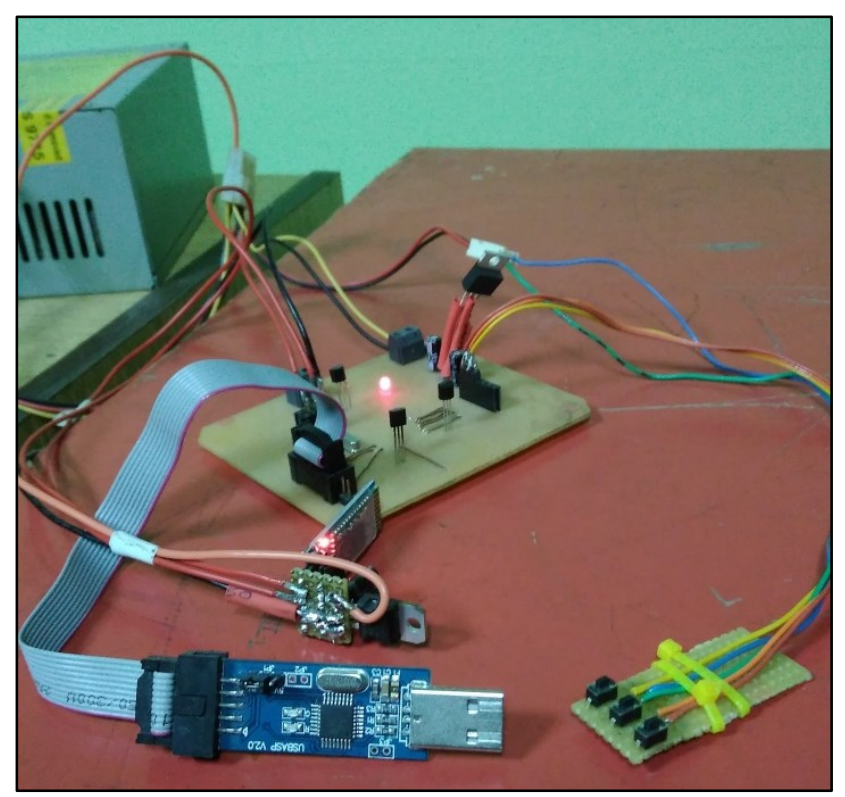

Slika 2: Prototip uređaj

\subsection{Mikrokontroler}

Upotrebljen je osmobitni mikrokontroler ATMega32A. Proizvodi ga kompanija Atmel. Sadrži 32 registra opšte namene, 32KB programabilne FLASH memorije u koju se smešta izvršni kod, 1024B EEPROM memorije koja se koristi za permanentno čuvanje podataka, $2 \mathrm{~KB}$ interne SRAM memorije za trenutno čuvanje podataka.

\subsection{Blutut komunikacija}

U želji da embeded sistem i korisnički interfejs budu potpuno nezavisni jedan od drugog u fizičkom smislu oblik komunikacije koji će se koristiti u ovom radu je bluetooth komunikacija.

Bluetooh komunikacija [2] predstavlja bežični komunikacioni standard za bežično povezivanje uređaja u okviru određene udaljenosti. Radni takt tj. frekvencija ovog standarda je 2,4GHz. Koristi se za prenos signala malih snaga. Brzina koju uređaji mogu ostvariti na udaljenosti do $10 \mathrm{~m}$ je $2 \mathrm{Mbs}$.

$\mathrm{U}$ ovom radu upotrebljen je bluetooth uređaj druge generacije pod oznakom HC-05. Radi na području od $2,4 \mathrm{GHz}$. U komunikaciji sa drugim uređajima može zauzeti i master i slave poziciju.

\subsection{Senzori}

U sklopu ovog rada fizička pojava koju treba detektovati jeste pojava položaja ili udaljenosti nekog objekta, u ovom slučaju automobila. Daljom analizom postojećih senzora[3] zaključeno je da je optimalno rešenje za ovaj problem bio šarpov senzor.

Simulacija senzora izvršena je tasterima kao što je prikazano na slici 2 .

Tasteri su respektivno povezani na pinove mikrokontrolera PA5 i PA6. Prvi će označavati prvi prolazak automobila i početak merenja, dok će drugi simulirati drugi prolazak i kraj merenja proteklog vremena.

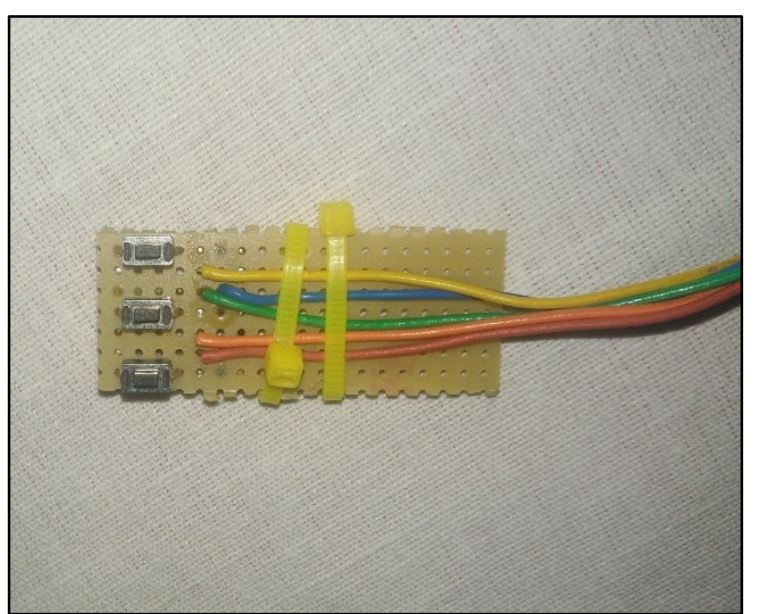

Slika 3: Realizacija senzora pomoću tastera

\section{SOFTVER I PROGRAMIRANJE MIKROKONTROLERA}

Softverski alati upotrebljeni za programiranje mikrokontrolera su:

- CodeVisionAVR

- $\quad$ Progisp 1.72

\subsection{CodeVisionAVR}

CodeVisionAVR[4] je integrisano razvojno okruženje i automatski generator programa, koji je dizajniran za Atmel familiju mikrokontrolera. S obzirom da okruženje podržava $\mathrm{C}$ kompajler i programiranje se radi u C programskom jeziku. Prethodnim podešavanjem neophodnih parametara u okviru automatskog generatora, utrošeno vreme programiranja se drastično smanjuje.

\subsection{Progisp 1.72}

Progisp je softverski alat koji omogućuje da se programski kod napisan $\mathrm{u}$ integrisanom razvojnom okruženju CodeVisionAVR uspešno prebaci na fleš memoriju mikrokontrolera.

\section{APLIKACIJA POLIGON}

U okviru ovog rada bilo je potrebno isprogramirati aplikaciju kojom će se upravljati praktičnim delom takmičenja u poznavanju saobraćaja, organizovanom pod okriljem zajednice srednjih saobraćajnih škola Republike Srbije. U sklopu upravljanja zadaci koje je aplikacija morala ispuniti su:

- definisanje takmičenja

- prijava takmičara

- merenje postignutog merenja

- $\quad$ skladištenje postignutih rezultata

- $\quad$ ukupan pregled postignutih rezultata

Aplikacija je razvijena u okviru okruženja Android studio. Aplikacija je dizajnirana tako da su korisnici podeljeni $\mathrm{u}$ dve različite grupe, admin i posmatrač, slika 4. 


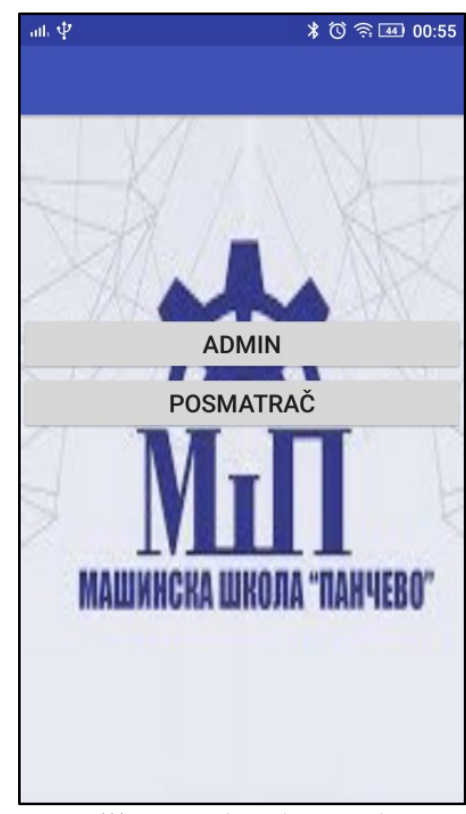

Slika 4: Izbor korisnika

Bitno je napomenuti da je po prirodi procesa samog takmičenja bilo neophodno pristup admin delu aplikacije omogućiti samo kontroloru i upravitelju takmičenja. Na taj način sprečava se kompromitovanje tačnosti podataka $i$ eventualne malvezacije. Pristup je moguć samo u slučaju pravilno upisanog korisničkog imena i lozinke, slika 5.

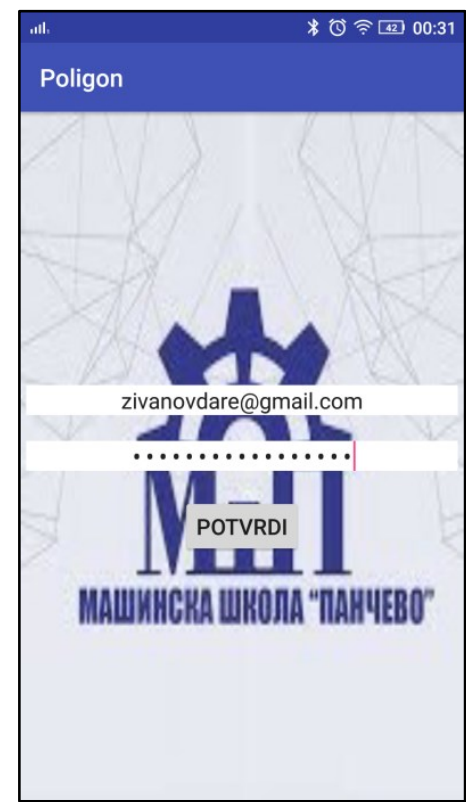

Slika 5: Unos korisničkog imena i lozinke

Drugi deo aplikacije namenjen je ostalim učesnicima i posmatračima takmičenja. Ti korisnici imaju samo mogućnost nadgledanja rezultata takmičara.

Osnovni princip prilikom programiranja aplikacije bio je da bude intuitivna $i$ da je neophodno što manje prethodnog znanja za korišćenje iste.

Kretanje kroz aplikaciju u slučaju izbora korisnika „POSMATRAČ““ zamišljen je da bude trivijalan. Korak koji potom sledi jeste izbor takmičenja, nakon čega će se izvršiti prikaz svih takmičara i njihovih rezultata. Kako se svi podaci čuvaju u bazi podataka, posmatrač nije ograničen samo na posmatranje trenutnog takmičenja, već ima slobodu pregleda svih prethodnih takmičenja.
Sama uloga admina odnosno kontrolora takmičenja puno je zahtevnija, pa je samim tim i izrada ove grane aplikacije bila teža.

Kako se svake godine menja domaćin takmičenja odnosno grad u kome se ono održava naziv samog takmičenja definisan je iz dva dela. Prvi je ime grada, a drugi datum održavanja. Ime grada se upisuje dok se datum bira iz menija gde je prvi ponuđeni datum trenutni tj. današnji.

Takmičari jedan po jedan prolaze kroz poligon takmičenja. Taj princip primenjen je i u aplikaciji. Celokupna pažna je posvećena uvek samo jednom takmičaru u datom momentu. Tako se $u$ aplikaciji takmičar prvo definiše upisom njegovih ličnih podataka kao što su ime i prezime i škola koju pohađa. Nakon toga se bira mod rada uređaja koji može biti automatski i manuelni i pristupa se merenju vremena, slika 6 .

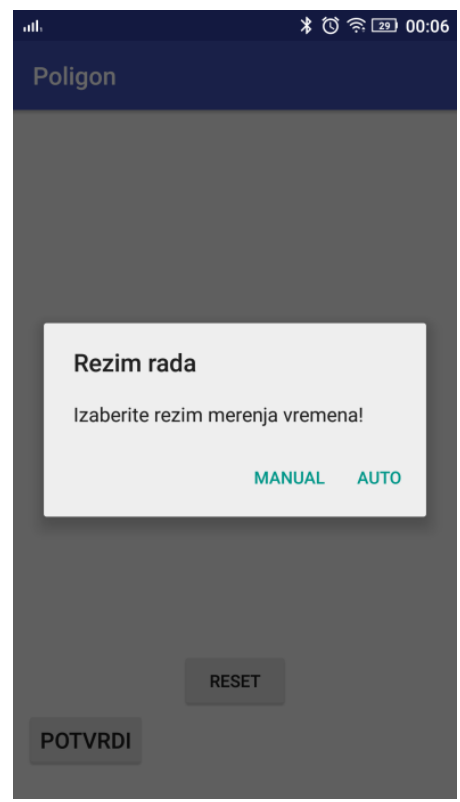

Slika 6: Režim rada

Potom sledi potvrda izmerenog vremena, čuvanje svih prethodno unešenih podataka za tog takmičara $\mathrm{u}$ bazu podataka kao i njeno ažuriranje. Time je proces takmičenja jednog takmičara završen i prelazi se na sledećeg.

Pored unosa novog takmičenja i takmičara omogućeno je i njihovo selektovanje i brisanje. Treba napomenuti da se izborom brisanja ne vrši stvarno uklanjanje podataka iz baze već se samo zabranjuje njihov prikaz u aplikaciji. Na taj način obezbeđen je povratak informacija ukoliko dođe do njihovog slučajnog brisanja.

\subsection{Firebase}

Podaci o takmičarima poput njihovih imena i prezimena, imena škole koju pohađaju i izmerenog vreme koje im je bilo potrebno za izvršenje zadataka na takmičenju čuvaju se u bazi podataka kompanije "Firebase".

\section{ZAKLJUČAK}

U ovom radu pokazano je da automatizacija procesa nije striktno vezana za industriju ili proizvodnju, a da je krajnji rezultat opet ušteda potrebnih resursa, smanjenje gubitaka, smanjenje grešaka, povećanje transparentnosti i 
dostupnosti podataka, povećanje ponovljivosti izvršenja zadataka, zadovoljstvo krajnjeg korisnika...

Ovaj proizvod je jedan moderan proizvod. U koraku je s vremenom, akcenat je stavljen na fleksibilnost i mobilnost kako korisnika tako i neophodnog uređaja za merenje proteklog vremena. Smanjeno je vreme utrošeno na popunjavanje većeg broja papira prilikom upisivanja takmičara u sistem takmičenja i popunjavanje njegovih ličnih podataka. Pojednostavljen je čitav taj proces i približen je današnjici.

Treba uzeti u obzir da proizvod ovog rada nije konačan $i$ da predstavlja samo prototip koji bi dalje trebalo testirati i prilagoditi korisniku i situacijama koje nisu bile predviđene pa samim tim nisu ni testirane. U pogledu postojećeg rešenja modifikacije se mogu vršiti kako u daljoj automatizaciji procesa takmičenja tako i $u$ mogućnostima koje sam korisnički interfejs pruža.

Postavljena je kvalitetna osnova za dalja unapređenja.

\section{LITERATURA}

[1] http://zss.edu.rs/images/Takmicenje/ Dodatak pravilnika dopunjen.pdf - Dodatak pravilnika takmičenja [2] Materijal sa predavanja, Industrijske mreže i protokoli, dr Gordana Ostojić

[3] Materijali sa predavanja, Elektropneumatika, dr Stevan Stankovski

[4] CodeVisionAVR User Manual

\section{Kratka biografija:}

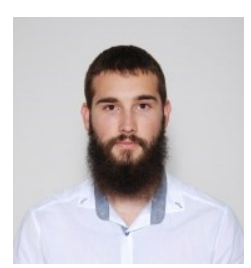

Darko Živanov, rođen 31. oktobra 1992. godine u Pančevu. Godine 2011. završava Srednju mašinsku školu „Pančevo“, tada oglednog smera Tehničar mehatronike ogled sa odličnim uspehom 5.00. Iste godine upisuje Fakultet tehničkih nauka u Novom Sadu, smer Mehatronika. Osnovne akademske studije završava 2016. godine sa prosekom 8.21. Odmah nakon toga upisuje Master akademske studije na istom smeru. Ispunio je sve ispitne obaveze za prosečnom ocenom 9.44. Od maja 2018. godine radi kao aplikativni i inženjer podrške u kompaniji za proizvodnju i inženjering EuroICC.

Kontakt: zivanovdarko@yahoo.com 